\title{
Hydropower and \\ End-Use Electrical Efficiency in China: State Support and Potential Contribution to Low-Carbon Development
}

\author{
DARRIN MAGEE
}

\begin{abstract}
This article examines Chinese state support for two 'new energies' - large hydropower and end-use efficiency - that aims to help meet ambitious national targets for renewable energy and emissions reduction. Large hydropower, while not particularly new, figures prominently in China's renewable energy targets and is considered key to achieving renewable output and carbon reduction goals. National policies promote widespread development of Gigawatt-scale hydropower cascades on China's major rivers, even though the negative impacts are significant and the operating capacities of large dams are often low. On transboundary rivers, China's dam development raises concerns downstream. Increasing the end-use efficiency of electricity represents a more subtle approach that holds great promise for managing demand and potentially curbing new supply. China's National Development and Reform Commission (NDRC) has overseen experimentation with utility-scale 'efficiency power plants' that free up inefficiently-used electricity, resulting in greater power availability on the grid. A study by NDRC's Energy Research Institute (ERI) estimated that a high penetration rate of LED lighting by 2020, once China completes its phase-out of incandescent bulbs, would alone save as much electricity annually as the Three Gorges Dam produces. This article demonstrates the potential for an efficiency-led approach to meeting China's electricity needs.
\end{abstract}

Keywords: China, Power Sector, Energy Efficiency, Hydropower, Energy Policy, Electricity

\section{Introduction: A Bright Idea}

In 2009, a researcher from China's Energy Research Institute (ERI), an arm of the National Development and Reform Commission (NDRC) that advises the NDRC and other key decision-making bodies about energy issues, published a report on light bulbs (Liu 2009). Specifically, the report examined different trajectories, with varying cost and 
technological assumptions, for meeting China's expected lighting needs by 2020, when low-efficiency incandescent bulbs are set to be completely phased out. Incandescent bulbs, whose design has been fundamentally unchanged since their invention in the late 1800s, do a poor job of converting electrical energy to light. At efficiencies hovering somewhere around 5 per cent, the remainder of the delivered electricity from these bulbs is wasted as heat which, despite providing some modicum of comfort in cold climates, is an irrational and uneconomical use of a system designed primarily for light.

The ERI study examined two scenarios, both involving completely displacing incandescent bulbs with a mix of compact fluorescent (CFL) and light-emitting diode (LED) bulbs by 2020. CFLs can produce the same amount of light as incandescents using approximately one-fifth of the energy. LEDs can do it for one-tenth of the energy. The study then estimated the annual electricity savings that would result, as compared to a base case that assumed incandescents were still part of the mix. Factoring in the predicted growth in lighting needs through 2020, the study's results were enlightening: the scenario that included higher penetration rates of LEDs due to cost and technological breakthroughs yielded annual electricity savings of some 85 TWh as compared to the base case. That figure is approximately equal to the annual output of the Three Gorges Dam, China's largest hydroelectric project and one of the most controversial in the world. ${ }^{1}$

Contorting an oft-heard joke, one might ask, 'How many light bulbs does it take to change China?' Simply put, changing light bulbs is the paramount example of what energy efficiency experts like to call the 'low-hanging fruit'. If a nationwide switch from incandescents to more efficient and readily available lighting technologies can effectively displace the annual output of China's largest hydroelectric plant, or of a dozen 1000-MW coal-fired power plants operating at a 90 per cent capacity factor, what effect might deeper end-use efficiency work aimed at even larger electricity users such as industrial pumps, blowers, and $\mathrm{HVAC}^{2}$ units have on electricity savings? The scalability of efficiency measures becomes quite interesting here, given that approximately half the world's industrial electricity use is consumed by pumps and fans (Lovins and Rocky Mountain Institute 2011: 139).

In addition to ERI, two other key actors influencing China's energy use and production decision-making processes are the State Council's National Energy Commission and the National Development and Reform Commission's National Energy Administration. This article 
examines the Chinese state's support for and the general situation of two so-called new energies (xin nengyuan), which are set to play a role in the decarbonisation of the Chinese economy: hydropower and end-use efficiency. Specifically, it analyzes state policies, progress and challenges in relation to large-scale hydropower and end-use efficiency in the power sector. With the fourth-largest total land area, elevation drops among the highest in the world, and more than 23,000 rivers with watersheds over $100 \mathrm{~km},{ }^{3}$ it comes as no surprise that China holds the world's greatest hydropower reserves, with gross potential estimated at some $694 \mathrm{GW}$, of which about $540 \mathrm{GW}$ is considered economically feasible by China's principal hydropower planning institute. ${ }^{4}$ By the end of 2013, China's installed hydropower capacity stood at roughly half that figure, approximately $280 \mathrm{GW}$, not including pumped storage plants and conventional hydropower facilities with power ratings lower than $6 \mathrm{MW} .{ }^{5}$ Yet some of that capacity may be under-utilized; the average utilization time of all hydropower in 2013 was only 3318 hours, ${ }^{6}$ which is less than half the 8765.81 total hours in one year, yielding a capacity factor of 37.9 per cent. $^{7}$

China also stands to gain significantly by improving end-use efficiency in all sectors, including the electrical sector. The simplest example of this type of 'low-hanging fruit', or what some energy experts call 'negawatts', involves nothing more challenging than changing light bulbs. In a textbook scenario where a 40 per cent-efficient coal-fired power plant delivers electricity to a 5 per cent-efficient incandescent light bulb via a transmission and distribution network that is 90 per cent-efficient, the overall efficiency of the end-use (i.e., lighting) is the product of those three efficiencies: here a meagre 1.8 per cent. Clearly, this is a staggeringly wasteful use of electricity. Yet traditional, centralized approaches have focused on improving power plants, which can at best lead to incremental improvements given the laws of physics and the limits of temperature and materials, and will exceed 50 per cent in only the best of cases. ${ }^{8}$ At the same time, replacing the wasteful incandescent bulb - which is, after all, based on technology more than a century old - with an LED bulb that uses one-tenth of the electricity to produce the same amount of light increases the efficiency of the entire process to 18 per cent. While there is still much room for improvement, that ten-fold increase in end-use efficiency means that 90 per cent of the fossil-derived energy that would formerly have powered that light bulb is now no longer needed. ${ }^{9}$ 


\section{China's Current Energy Situation}

China's quest for secure, reliable and low-carbon energy sources has garnered much media attention in recent years. At times the attention has focused on the significant challenges the Chinese government faces in curbing widespread environmental degradation, most notably the pollution of its waters, air and eventually its citizens, with the by-products of rapid, intensive and extensive industrial development and modernization. The most obvious recent example is the suffocating air pollution that has enveloped eastern population centres and economic engines like Beijing and Shanghai since early 2013. At other times, however, the attention has come as a result of the country's apparent progress in the development of non-carbon energy sources, which has, despite certain setbacks, been impressive. Perhaps most noteworthy has been China's deployment of utility-scale wind power installations, which led to an annual doubling of installed capacity between 2006 and 2009, and by $2013(91,412.89 \mathrm{MW})$ the level of installed capacity was more than 267 times greater than it was in 2000 (341 MW). ${ }^{10}$

According to China's National Bureau of Statistics, China's total energy consumption in 2012 amounted to 3,617,320,000 TCE. ${ }^{11}$ The United States Energy Information Administration (EIA) puts that figure at a comparable, though higher, 109.620 Quads (3,946,253,796 TCE) for the previous year. ${ }^{12}$ This latter figure is roughly equivalent to 1.12 times the United

FIGURE 1. China's Electricity Mix

\section{China's Electricity Mix (2011)}

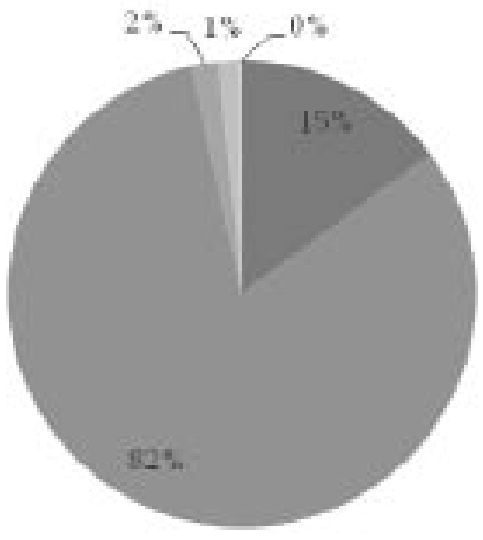

mydroelectricily Prodistion

EThermal Electracity Production

Nucleax Electricity Production nWindEloctricit. Froduction Elactricity Lruports

Source: National Bureau of Statistics. 
States' consumption of 97.469 Quads, or some 140 times Denmark's total energy consumption that same year..$^{13}$ As shown in Figure 1, fossil fuels continue to comprise the vast majority of China's electricity mix. Although the rapid increases in renewables over the past decade have eroded the fossil share somewhat, the overall trend in energy production since the start of the Reform Era (1978), and especially since the highgrowth phase that began in the early 1990s, has been one of heavy reliance on an increasingly large gross quantity of fossil fuels (see Figure 2).

FIGURE 2. Energy Consumption by Type

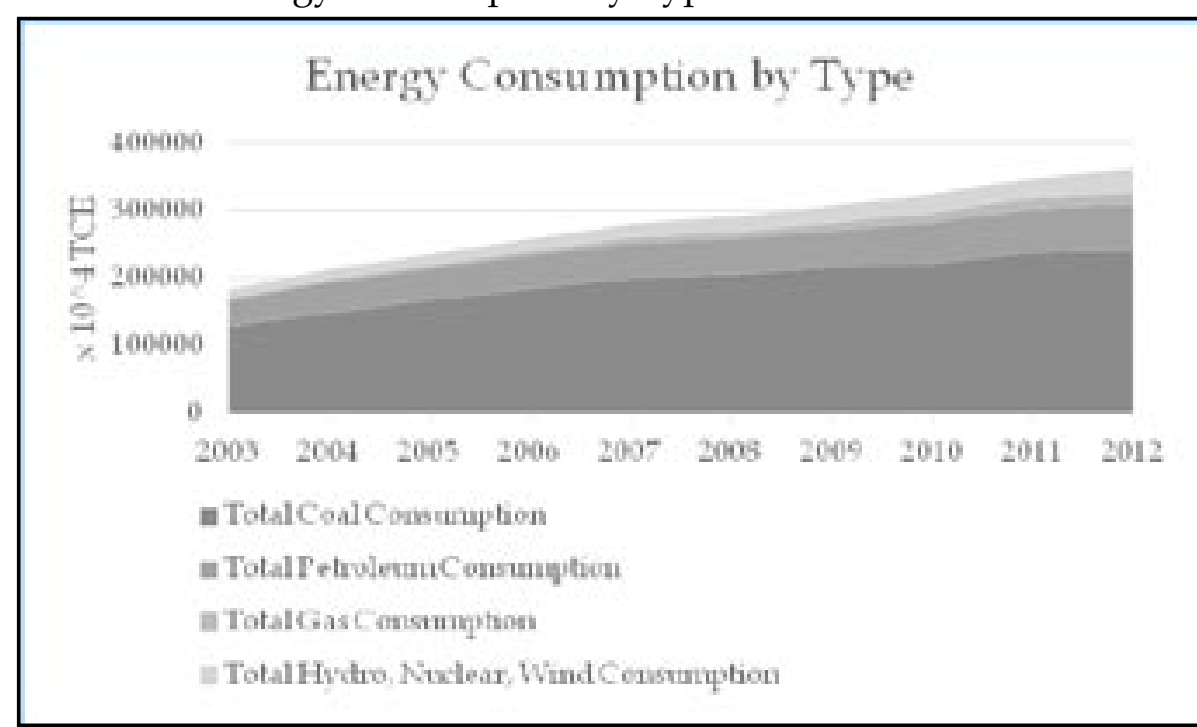

Source: National Bureau of Statistics.

\section{Limits to Coal-Fired Development}

There are clear constraints to the business-as-usual approach to meeting China's electrical energy needs by building more thermal power supply. Not least is China's physical geography, as much of the coal that currently powers China is mined in the northeast, while much of the water that provides the steam and cooling in thermal power plants is in the southeast. At the same time, much of the mining, processing and combustion of coal for electricity or factory processes takes place in provinces west of major centres of population and political power like Beijing and Tianjin. Prevailing winds then carry particulates and other pollutants eastward, making coal a political liability, both domestically and internationally, as emergency hospital visits due to respiratory distress surge as far away as Seoul, Korea when eastern China has bad air days (Kim et al. 2008). 
According to the EIA, China's total carbon dioxide emissions in 2011, the most recent year for which data are available, reached 8715.31 million metric tons. ${ }^{14}$ Air pollution in eastern cities has already prompted central planners to accelerate development of new coal bases much farther west, where pollution is less likely to affect eastern metropolises. However, these are also areas where the water resources necessary for thermal power production are much less abundant. ${ }^{15}$

In addition to simple friction of physical geography, it is clear from a climate change, air quality, human health or energy security perspective, that fossil fuels' share of both primary energy and electricity will have to shrink dramatically in the coming decades. Evidence suggests that the central leadership of China understands this well, not only because reliable energy sources are vital for sustaining economic development and lifting more of China's population out of poverty, but also for broader socio-political reasons. For the leadership, environmental degradation has to be seen as an increasingly important variable in the equation that determines the level of so-called social harmony (shehui hexie), or absence of social unrest: the most coveted of goals for the Chinese Communist Party seeking to maintain its political legitimacy. ${ }^{16}$

In addition to the air pollution that has smothered China's cities in the east in recent years, official data show that one-third of China's river segments tested in 2012 were contaminated at levels unfit for direct human contact (Ministry of Water Resources of the PRC 2014).${ }^{17}$ The situation for lakes and groundwater is much worse: of 112 major lakes and 1040 groundwater test wells, 80 lakes (72\%) and 790 wells (76\%) yielded water unfit for direct human contact (Ministry of Water Resources of the PRC 2014). Toxic pollutants, such as heavy metals, readily make their way into the food chain, as evidenced by the presence of high levels of cadmium in more than half of rice samples taken in southern China. In their oxidized forms, such metals are exceedingly deleterious to human health; the science on this is clear, yet the behaviours have yet to change. From a human development perspective, the services provided by that energy-such as warmth, light and mobility - will still need to be delivered, only by renewable, less polluting and more sustainable energy sources.

\section{Policy Environment}

To this end, the Chinese government has enacted a number of laws, policies and projects that seem, at least on the surface, to hold some promise for improving energy efficiency and curbing pollution (see 
Table 1). Perhaps most important among them is the Renewable Energy Law of 2005 (revised in 2009), which, among other things, made commitments to purchase all renewable electricity produced (Art. 14), revised renewables subsidies (Art. 24) and specified penalties for grid companies that failed to connect renewables to the transmission and distribution network (Art. 29).${ }^{18}$ Shortly thereafter, the Top 1000 Energy-Consuming Enterprises Program targeted 1000 enterprises responsible for 33 per cent of national energy usage and 47 per cent of industrial energy usage. In 2009, the government set a goal to reduce carbon intensity by $40-45$ per cent (off a 2005 baseline) by 2020, with an intermediate target of a 17 per cent reduction by 2015. Given the preponderance of coal in China's energy mix, a reduction in energy intensity is roughly equivalent to a comparable reduction in carbon intensity. Many of the prescriptions laid out in these various policies are now simply referred to collectively as part of the 'Energy Savings and Emissions Reduction' (jieneng jianpai) policy, now a familiar slogan in energy and environment circles.

TABLE 1. Policy Environment Support for Electrical Efficiency

\begin{tabular}{|l|l|}
\hline Policy / Project / Plan & Date(s) \\
\hline Energy Conservation Law & 1997 (Rev. 2007) \\
\hline Renewable Energy Law & 2005 (Rev. 2009) \\
\hline Top 1000 Energy-Consuming Enterprises & 2005 \\
\hline $\begin{array}{l}\text { Medium- and Long-term Development Plan for } \\
\text { Renewable Energy }\end{array}$ & 2007 \\
\hline Promote Big, Squash Small & 2007 \\
\hline 11th Five-Year Plan for Renewable Energy & $2006-2010$ \\
\hline Policy on Energy Savings for Civilian Buildings & 2008 \\
\hline 12th Five-Year Plan for Renewable Energy & $2011-2015$ \\
\hline Incandescent Bulb Phase-Out (3 stages) & $2011-2020$ \\
\hline
\end{tabular}

The Medium- and Long-term Development Plan for Renewable Energy in China (2007) built upon the foundation laid by the Renewable Energy Law, mandating that at least 15 per cent of total energy consumption in 2020 must come from renewable sources. Whereas that specification initially targeted primary energy, it was later revised to target final energy instead. ${ }^{19}$ This implies an even greater penetration of renewables than was outlined in the initial primary energy target (Martinot and Li 2010). Importantly, the revised goal specifies 'nonfossil' sources (as opposed to the earlier use of the term 'renewable'), thus bringing nuclear, which presently contributes just two per cent 
of China's electricity but is slated for massive expansion, into the mix. Large hydropower plants, which have faced scrutiny for their societal and environmental impacts, are also included, as they are not technically considered to be greenhouse gas-producing installations during normal operation. One strength of the 15 per cent mandate is that it sets a target for actual electricity output, not simply installed capacity. In recent years, total installed wind capacity in China has roughly doubled annually, growing faster in many cases than the grid infrastructure needed to support and utilize it. Focusing on output rather than installed capacity takes into consideration grid connectivity, and the extent to which some wind turbines might be standing idle or 'wasting wind' (qifeng) due to curtailment or lack of grid connectivity.

In 2007, the State Council announced an approach to curbing emissions and increasing power generation efficiency that came to be known as the 'Promote Big, Squash Small' (shangda yaxiao) policy. ${ }^{20}$ The policy targeted the country's oldest and least efficient coal-fired power plants (defined the policy as: 'in principle, those rated under $300 \mathrm{MW}$ per generator unit'), slating them for closure and, in many cases, demolition. At a time when foreign news media frequently carried reports of 'one power plant per week' being completed in China, the 'Promote Big, Squash Small' policy officially forbade new construction of small coal-fired power plants in areas with modern power grid coverage, the logic being that cleaner power sources, even if not local, would be gridinterconnected and therefore available. Moreover, the policy instructed grid operators to refrain from providing grid connectivity or related services to plants that were constructed without permits or otherwise operating illegally. High-profile demolitions of cooling towers broadcast on television and the internet (see Figure 3) were clearly intended to send a message that the central government was serious about reducing emissions and energy intensity. Between 2007 and 2010, more than 70 GW of coal-fired power plants were shut down.

Other policies targeted narrower sub-sectors of the economy but nonetheless form part of China's overall electrical energy use landscape. The 'Policy on Energy Savings for Civilian Buildings' (2008) set targets for things such as lighting, controls and insulation for residences, government office buildings, and commercial and service facilities. Certain others were designed as much to increase domestic consumption of durable goods as to promote energy-efficiency. Indeed, the first two priorities of the policy to 'Replace Old Household Appliances with New' (jiadian yijiu huanxin) are 'to promote expansion of consumer demand 
FIGURE 3. Series of Photos Showing the Cooling Towers of Two 125MW Units at Huaneng's Changxing Power Plant in Zhejiang Province being Demolished in September 2010

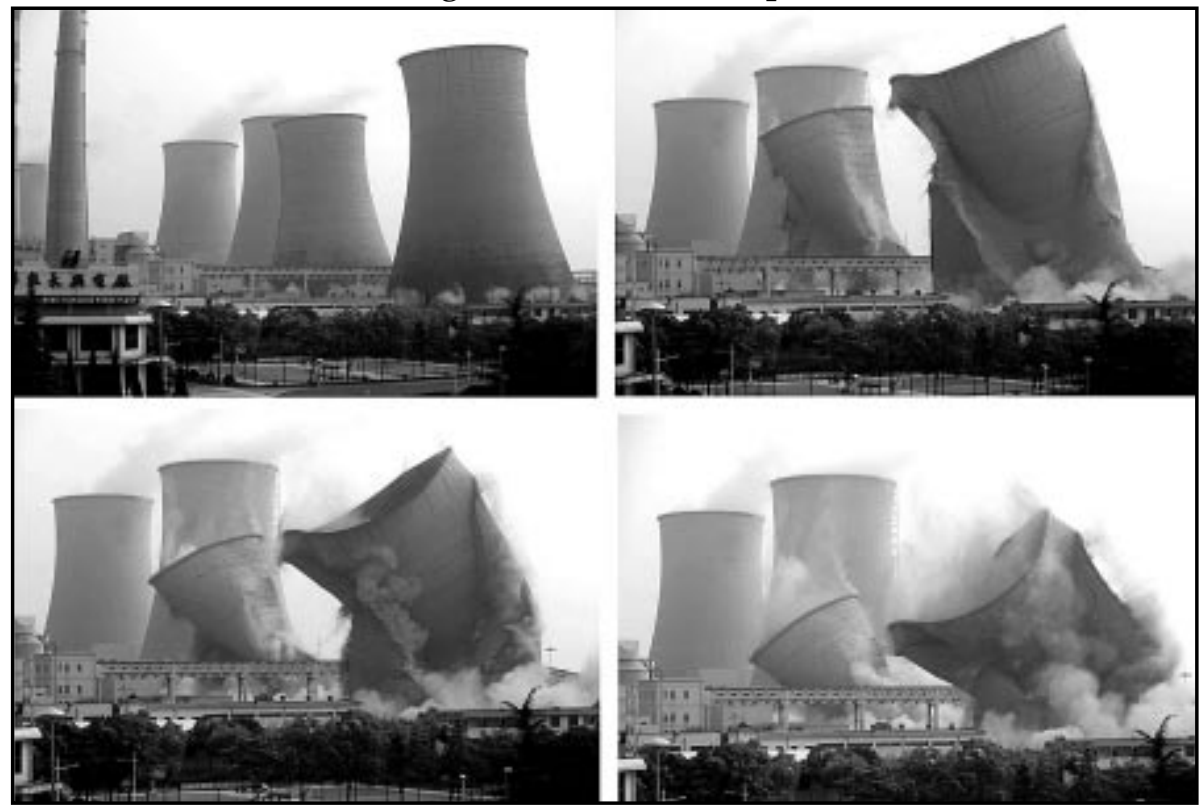

Source: http:/ /yz.2118.com.cn/news/Html/2010-09-17/64692_1.htm.

and increase efficient use of resources, ' in that order. ${ }^{21}$ Similar consumption-oriented policies with a veneer of energy efficiency include the 'Energy-Efficient Appliances' project (jieneng chanpin huimin gongcheng), which offered subsidies on the most efficient models of air-conditioners and other consumer goods, ${ }^{22}$ and the 'Household Appliances to the Villages' policy (jiadian xiaxiang), designed specifically to promote consumption of simple household appliances in rural areas. Still others, aimed at increasing passenger vehicle fuel economy and similarly laudable goals, are beyond the scope of this article.

\section{The Promise and Peril of Large Hydropower in China's Energy Goals}

China has the world's greatest hydroelectric potential, with technically and economically feasible capacity frequently estimated to be potentially as high as $540 \mathrm{GW}$, as previously noted. Yet much of that capacity has yet to be developed; according to the China Electricity Council, the country had approximately $280 \mathrm{GW}$ of installed capacity at the end of $2013 .{ }^{23} \mathrm{By}$ comparison, the EIA puts the installed capacity of the United States at 78 
GW at the end of 2011, a figure that has begun to decline slightly due to dam closures and removals. The capacity of Europe is roughly $171 \mathrm{GW}$, and that of Denmark a modest $9 \mathrm{MW}$. China's hydropower installations range from kilowatt-scale micro-hydro stations that provide electricity to rural villages, to the massive Three Gorges Dam with its $22.5 \mathrm{GW}$ of installed capacity, to cascades of multiple mega-dams such as that on the Lancang (upper Mekong) in Yunnan Province, which already exceeds $10 \mathrm{GW}$ and will likely grow to nearly double that in the coming decade. Upstream of the Three Gorges Dam, a cascade of nearly a dozen dams on the Jinsha (upper Yangtze) is underway. If completed, the total installed capacity of that cascade will be four to five times that of the Three Gorges project itself.

Hydroelectric potential depends on elevation drops and river volumes. Actually developing that potential, however, depends on financial capital, technical expertise, and a favourable policy environment. China has plenty of all three. Unlike the situation in many less-developed countries elsewhere in the world, most of China's large dams are selffinanced, not reliant on development funding and therefore not subject to the same reporting and transparency requirements. Dam construction companies, all of which were formerly part of the Ministry of Electric Power (Magee 2006), benefit from a number of policy supports and, perhaps more importantly, from a legacy of direct access to key decision-makers in the National Development and Reform Commission and the State Council. At the founding of the People's Republic of China in 1949, China had two large dams. Now, most analysts put that figure at between 5,000 and 25,000, depending on how one actually categorizes a large dam. In recent years, China's dam industry has become the major player in constructing dams overseas, following a policy that encouraged power companies and their hydropower subsidiaries to Go Outward (zou chu qu). Domestically, policies such as the Western Development Campaign (xibu da kaifa), Send Western Electricity Eastward (xidian dongsong), and Save Energy, Reduce Emissions (jieneng jianpai) have played important roles in facilitating hydropower development in western regions replete with high mountains and big rivers.

While China's present and projected figures for installed hydroelectric capacity are impressive, the actual role hydropower plays in the overall electricity mix in China is much more modest, with total output of hydroelectricity accounting for just six per cent of total primary energy and roughly 15 per cent of total electricity produced (687 TWh in 2011). Developers like Huaneng, Huadian and China Three Gorges Project 
Corporation have undertaken dozens of high-profile, often controversial mega-dams in the past two decades in the southwest of the country. In almost all cases, developers claim that these dams will have relatively high guaranteed electricity output levels, equating to capacity factors between 40 and 50 per cent or higher. For instance, according to official figures, the 4200-MW Xiaowan dam on the Lancang (upper Mekong), the tallest concrete arch dam in the world, is expected to have an average annual output of some $19 \mathrm{TWh}$, equivalent to a capacity factor of 51.6 per cent. ${ }^{24}$ Yet, using the EIA figures for total installed capacity and total hydroelectricity output for the entire country in 2012 (249 GW and $687 \mathrm{TWh}$, respectively), one arrives at an average capacity factor of only 31.47 per cent, ${ }^{25}$ or about two-thirds the world average for hydropower (IPCC 2011: 441). The actual build-out of China's hydropower, then, will likely be more extensive than it otherwise would be in order to compensate for low capacity factors and allow maximum flexibility and dispatchability if hydropower is to contribute optimally to reducing carbon dioxide emissions.

\section{The Dam Conundrum: Hydropower's Negative Impacts}

These data suggest that significant trade-offs may arise due to overbuilt dams that inundate land near rivers, which is often relatively flat and fertile, in a country where arable land is already scarce. As the World Commission on Dams (2000) reported in its landmark study, large dams around the world come with numerous and significant social and environmental costs, and almost uniformly fail on a range of benchmarks, ranging from construction cost overruns to actual power produced to cost overruns. Moreover, in light of the extremely rich cultural and biological diversity in areas of south-western China, where the most ambitious dam building efforts are underway, the vulnerability of human- and non-human communities may be even greater. One study found, for instance, that local residents' inability to converse easily in Mandarin, coupled with their lack of formal education and technical skills, makes it exceedingly difficult for them to participate fully in modern industrial economic activities (Brown, Magee, and Xu 2008). Moreover, China's resettlement policies do not require the resettlement of whole communities into the same new location, which frequently leads to the rupture of the social ties that form the basis of rural society and on which families, trust and even economic relations such as lending depend. While there is some anecdotal evidence that compensation 
and resettlement conditions are improving, other evidence suggests the resettlement process is still carried out almost as an afterthought, especially from a budgetary perspective, in many cases.

The impacts of dams, both positive and negative, vary geographically. This is perhaps more true for dams than for other major infrastructure projects, especially large dams whose reservoirs stretch for tens if not hundreds of kilometres. While communities near the dams are displaced and even may see their existing electrical infrastructure submerged or otherwise disrupted by dam projects, users on the grid hundreds and even thousands of kilometres away benefit from a marginal increase in power availability and grid reliability. The literature is replete with studies documenting the negative impacts of dams (Scudder 2005; McCully 2001; McNally, Magee, and Wolf 2009), yet many of these impacts (such as reduction of biodiversity or increases in geopolitical tensions) are difficult to measure and therefore do not figure, at least not explicitly, in impact assessments. Moreover, the environmental impact assessment process in China is notoriously weak, with assessments often conducted by individuals hand-picked by the power companies, and the resulting impact statements are often copied almost verbatim from one project to another.

In an attempt to make those impacts more visible and quantifiable, one interdisciplinary team of scholars developed the Integrated Dam Assessment and Modelling framework and software model to model and visualize three types of impacts: biophysical, socioeconomic, and geopolitical (Tullos et al. 2010; Tullos et al. 2013). The theoretically and empirically grounded framework allows users to assess not only the objective positive and negative magnitude of 21 impacts, but also to assign a salience value to each one, reflecting different users' subjective evaluation of the importance of each impact and, in principle at least, enabling those different users to identify key points of agreement and disagreement in order to facilitate more informed and more transparent decision-making. Application of the model to pre- and post-dam communities in Yunnan Province, a focal region for large-scale hydropower cascade development on the Lancang (upper Mekong), Jinsha (upper Yangtze), and $\mathrm{Nu}$ (upper Salween) demonstrated that communities in the Nu River gorge are, for the reasons noted above (language, technical training, and so on) especially vulnerable to the highly localized negative impacts hydropower development.

Thus large-scale hydropower presents an especially difficult policy choice for the generation of China's leaders looking to address a 
number of troubling challenges, ranging from rural livelihoods on- and off-farm, to reducing carbon intensity of GDP and combating climate change. As noted above, the fact that China holds the world's greatest endowment of technically feasible hydroelectric potential in itself presents a powerful incentive to harness that energy before it is transported to the sea. If current trends continue, China's electricity mix in the coming decades will derive from an 'all of the above' option that embraces new energies such as wind power, solar thermal power, and photovoltaics, while continuing to prioritize more traditional power sources such fossil thermal (coal and natural gas primarily), nuclear, and large-scale hydropower. In addition, despite advances in sun and wind forecasting, shifting or smoothing peak electricity demand (load), and using large 'balance areas' to compensate for the intermittency of solar and wind power, grid operators and power purchasers often see spinning reserves (i.e. base-load power plants idling at low capacity to provide system redundancy) as the only reliable way of countering that intermittency. Even on sunny days or windy nights when solar and wind power generators are operating at high capacity factors, a fraction of traditional generators, including thermal and hydropower, must be kept on standby so that those resources may be quickly and easily dispatched to meet any spikes in load or any drop in available power resulting from clouds or still air. Failing to do so can lead to brownouts, blackouts and loss of economic activity. If some of the negative impacts of overbuilding China's power supply infrastructure are to be avoided or at least mitigated, then power sector decision-makers must pay serious attention to alternative yet proven approaches for curbing demand, smoothing the electricity load profile and compensating for renewables' intermittency.

\section{The Case of Three Gorges Dam}

The Three Gorges Dam, in all its concrete and steel splendour and obscenity, is unmistakably an engineering masterpiece. It may well turn out to be a masterpiece of an engineered mistake, as the problems with slope instability, resettlement, corruption, habitat destruction, sedimentation and even reservoir-induced seismicity already seem to suggest. Yet Three Gorges Dam stands alongside other dams like Brazil's Itaipu, Egypt's Aswan High Dam, and the United States' Hoover Dam as a testament to modernization, to humans' attempts to harness rivers, master nature and inscribe our mark on the landscape (Kaika 
2006; McCully 2001). A flood control and power generation structure across the Yangtze at Three Gorges had long been in the forefront of the minds of Chinese leaders and hydraulic engineers alike, and now it stands as China's second Great Wall, symbol of the dramatic modernization that has swept much of China over the past three decades of the Reform Era.

At 22.5 GW of installed capacity, the power machinery of the Three Gorges Dam is equivalent to that of nearly 20 large, modern coal-fired power plants at 1,000 MW apiece. The dam produces some 85 TWh of electricity per year, offsetting approximately 59 million metric tons of carbon dioxide that would be produced were that electricity to come from coal-fired thermal power plants. ${ }^{26}$ Yet such a claim is basically meaningless, since, as noted above, China's 'all-of-the-above' approach to electricity generation means that the Three Gorges Dam, like the dozens of other Gigawatt-scale hydroelectric dams being built around the country, are supplements to, rather than replacements for, fossil-powered electricity generation. Moreover, the methane emissions from decaying biomass in the dam's 700-km-long reservoir are likely significant; one study estimated emissions arising from marshes in the reservoir drawdown area alone $\left(350 \mathrm{~km}^{2}\right)$ to be some 20,556 metric tons per year, not a trivial figure given methane's potency as a greenhouse gas (Chen et al. 2009). Nevertheless, for a host of reasons good and bad, the dam has drawn the attention of people around the world, attracting visiting official and business delegations, along with millions of domestic and international tourists each year. During the intense flooding of 2010, the recently completed Three Gorges Dam became a media darling, feted for controlling the surging waters of the Yangtze and preventing what would likely have been significant losses of life and property downstream. Photos such as the one shown in Figure 4 have become commonplace in Chinese and international media.

\section{End-Use Efficiency}

Changing light bulbs is less photogenic than mega-dams, but no less reasonable or valuable - if pursued vigorously and at scale - in meeting China's electrical energy needs in the coming decades. As noted above, the capacity factors for many of China's hydroelectric facilities, the cornerstone of low-carbon, non-fossil targets, are below world averages. This means that the financial, societal and ecological costs per kilowatthour of electricity produced from mega-dams are inordinately high. 
FIGURE 4. Three Gorges Dam Discharging Water

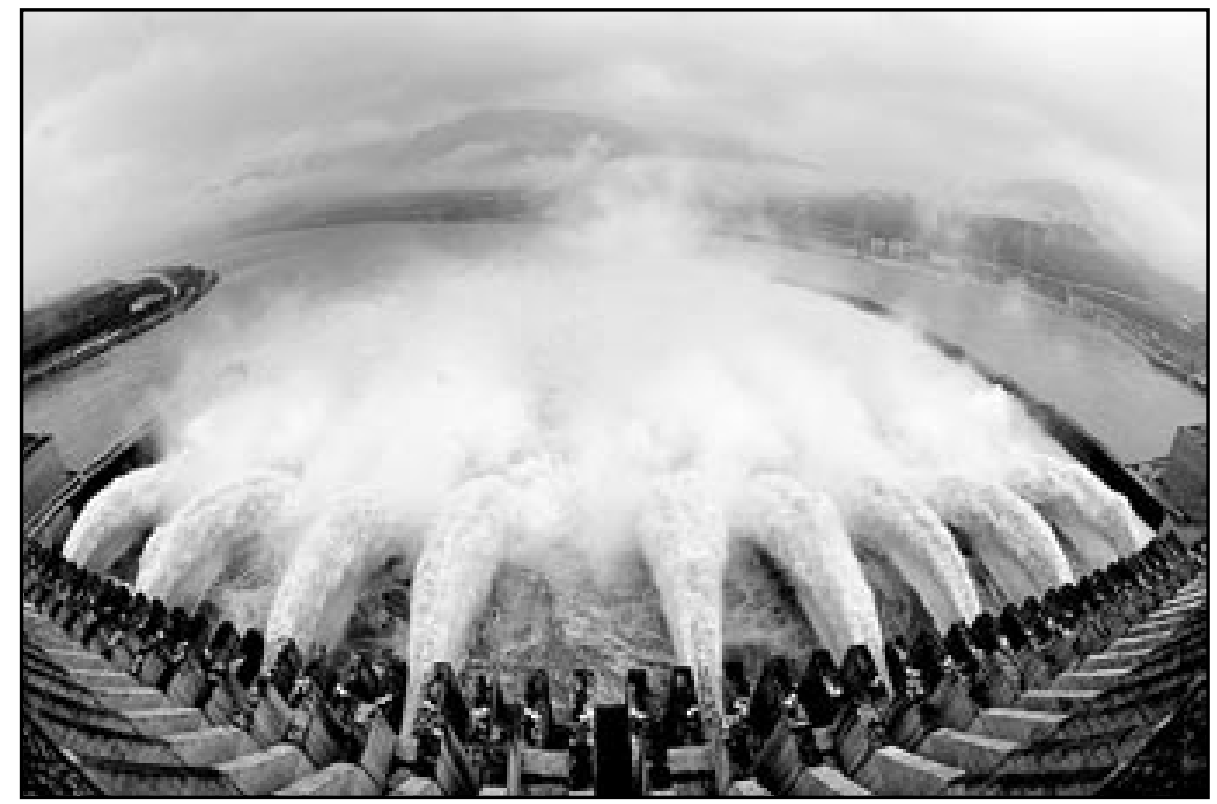

Source: Reuters; Retrieved from http://www.theguardian.com/environment/gallery/2010/ jul/21/ three-gorges-dam\# $/$ ?picture $=365062666 \&$ index $=0$.

Increasing end-use efficiency of electricity usage, meanwhile, effectively crowd-sources the solution to meeting China's rising demand for electricity by empowering and encouraging end users, from consumers to factories to municipalities, to implement practices and technologies that dramatically improve the utility of delivered electrical energy. Most, if not all, of the technologies involved are off-the-shelf, proven and costeffective technologies, and are not dependent on elusive technological breakthroughs, such as nuclear fusion.

Obviously, changing light bulbs is only part of the solution and is intended here as a proxy for a wide array of end-use changes that reduce and/or shift electrical loads. These include technologies and practices such as smart grid infrastructure, that monitors and manages variations in load while sending signals about real-time electricity prices; smart appliances and other equipment that react to those real-time price signals and shift their operations accordingly; variable frequency motors in factories that deliver precisely the amount of motive power needed for a specific task; and improved insulation and building design that reduces the need for air-handling and space conditioning. This last item is especially important in southern China, where peak annual demand for electricity comes in summer, when factories and urban areas crank up air conditioners to stave off the subtropical heat and humidity. That 
peak in electricity demand corresponds with a peak in the need for flood control, as the torrential rains of summer monsoons soak southern China and run rapidly off sparsely vegetated slopes and into the rivers. Simply put, operations for the same 'multipurpose' dam cannot be simultaneously optimized for flood control and power generation.

The policy environment for curbing electrical demand through demand-side-management (DSM) ${ }^{27}$ practices might be described as favourable yet tentative. Part of this stems from the financial complexities of DSM. In a world where power generators are incentivized to sell kilowatthours, the incentives for curbing demand for those kilowatt-hours are not always apparent, and the payoffs resulting from improved end-use efficiency do not by default accrue directly to power providers. Those payoffs to power providers do exist, however, since although end-use electricity is often purchased at a fixed price per kilowatt-hour, the cost of producing each kilowatt-hour can vary dramatically, simply because the marginal cost of producing an extra kilowatt-hour at midnight, when demand is low, from a base-load thermal power plant operating at 80 per cent capacity is far lower than that of producing a kilowatt-hour on a hot summer afternoon from an expensive gas turbine peaker plant $^{28}$ responding to an unexpected surge in demand or failure of a power plant or some other critical power grid component. In the United States, the cost for producers to provide peak electricity can be several times higher per kilowatt-hour than that of the midnight base-load, even though consumers generally do not see that increased cost reflected in their price except in the case where smart grid and variable pricing technologies and regimes are in place, as described below.

\section{Scaling the Light Bulb Effect: Efficiency Power Plants}

Yet at least some energy thinkers in China seem to appreciate, even if they underestimate, the potential for demand-side solutions to play a role in China's electricity future. Perhaps one of the clearest examples for that appreciation can be seen in the efforts to identify and 'construct' so-called Efficiency Power Plants (nengxiao dianchang). This effort, which first gained traction around 2005 in Guangdong and 2008 in Jiangsu, embraces and seeks to operationalize the concept of the negawatt, or energy saved rather than generated. The EPP project, jointly undertaken by the National Development and Reform Commission (NDRC) and the Natural Resources Defense Council (NRDC) with funding from the Asian Development Bank (ADB), scales up the notion of changing 
light bulbs by incentivizing massive electricity users such as factories and municipalities to improve efficiency in their usage. ${ }^{29}$ The value in such efforts lies not only in the easily quantified savings from lower electricity bills for those end users, but also - and more importantly - in the resources not consumed at the power plant to inefficiently produce electricity. Clearly, this has important implications in terms of avoided $\mathrm{CO} 2$ emissions in the case of coal-fired or natural gas-fired power plants. According to one report, sixteen enterprises in Jiangsu received funds for energy efficiency upgrades, resulting in a total savings of 110,890 MWh over the course of the year, ${ }^{30}$ roughly equivalent to the output of a $100 \mathrm{MW}$ coal-fired power plant operating at 80 percent capacity for two months, without factoring in transmission, conversion, or distribution losses. ${ }^{31}$ Displacing two months of plant operation would equate to some 50 metric tons of coal not combusted if the plant were operating with 40 per cent efficiency. ${ }^{32}$ According to the US Environmental Protection Agency, those coal savings would, in turn, save some 76,000 metric tons of climate-altering $\mathrm{CO} 2$ from being emitted into the atmosphere. ${ }^{33}$

One example of a pumping loop in a factory is illustrative of the energy-savings potential of increased end-use efficiency (Lovins and Rocky Mountain Institute 2011: 142). In a typical setting where electricity is delivered from a thermal power plant via transmission and distribution lines to a factory, the energy in that electricity must then operate a motor, whose motive forces passes through a drivetrain and to a pump, in order to finally move the liquid or gas through a piping loop which, depending on its design, might have lots of straight and wide pipes (less friction, therefore more efficient) or, conversely, lots of narrow pipes with right-angle turns (more friction, therefore less efficient). As shown in Table 2, the inefficiencies in each step compound to create as much as a 90 per cent loss of the energy input at the power plant. Saving one unit of energy at the end of the process by, for instance, straightening and widening pipes in the pumping loop, can save 10 units or more back at the power plant. According to the China Electricity Council, China's heavy industry used 3,209.2 TWh of electricity in 2013, while light industry used 637.9 TWh. Not only were both these figures up more than six per cent from the previous year, they also accounted for 60 per cent and 12 per cent, respectively, of the entire country's 2013 electricity use over all sectors. Improvements in pumping loops, lighting, space conditioning, controls and similar areas across the industrial sector that led to a modest 20 per cent reduction in end-use electricity, then, would mean a savings of 769 TWh in delivered (end-use) electricity at the factory, 
and roughly ten times that at the thermal power plant. ${ }^{34}$ That figure, in turn, is approximately equivalent to the amount of hydroelectricity produced by all of China's hydroelectric dams in $2013 .{ }^{35}$

TABLE 2. Energy Loss in a Pumping Loop

\begin{tabular}{|l|c|}
\hline Process Component & Energy Loss (\%) \\
\hline Power plant & 67 \\
\hline Transmission and Distribution & 10 \\
\hline Motor & 10 \\
\hline Drivetrain & 2 \\
\hline Pump & 25 \\
\hline Throttling Valve & 33 \\
\hline Pipe & 20 \\
\hline
\end{tabular}

Source: Adapted from Lovins \& Rocky Mountain Institute (2011: 142).

According to academic studies and media reports, the EPP approach seems to have gained some traction not only in Guangdong and Jiangsu, but also in Beijing, Shanghai, Hebei, Sichuan and Chongqing. ${ }^{36}$ NRDC reports an ambitious EPP project in Hebei that aimed to identify 1000 MW (1 GW) of electrical capacity in that province from 2009 to 2013. One year in, however, the project had only accumulated one-tenth of that amount, suggesting that at least some of the so-called low-hanging fruit in energy savings might not be so readily available or apparent. Two structural impediments likely explain why the EPP approach has yet to be more widely deployed or to produce more savings. First, as noted above, are financing questions that, at their most basic level, revolve around the question of who pays the up-front costs for utilityscale efficiency upgrades. Some innovations are being made, however, in order to advance EPP work without the support of outside funding agencies such as the Asian Development Bank (Yin and Wen 2013). Such innovations could include a small surcharge on every kilowatt-hour of electricity produced by utilities, which would pay into a fund used to support or subsidize end-use efficiency upgrades. Second, energy prices in China, including electricity prices, are suppressed, so energy is fairly cheap to end users, thus further disincentivizing upgrades that factory managers or municipal leaders might see as prohibitively expensive, or changes in practices that might seem logistically or culturally challenging. Finally, different standards for Evaluation, Measurement and Verification $(\mathrm{EM} \& \mathrm{~V})$ across administrative regions and projects may complicate EPP work in the short term. 


\section{Making the Grid Smarter}

Smart grid technology represents another promising solution to meeting a portion of China's current and projected electricity needs by curbing peak demand and therefore reducing the need for rapidly-dispatched peaker plants whose operating costs per kilowatt-hour generated, as noted above, can be quite high. So-called Demand Response (DR) activities, in which end users shift electricity-intensive operations to a time of day when demand is lower, are a key component of making this strategy work, and are dependent on a grid that transmits not only electricity, but also information. China's State Grid Corporation, one of the two major grid operators, has undertaken large-scale smart meter installations across the country in a three-phase programme aimed at realizing a nationwide smart grid by 2020. Investment in 2013 alone topped USD $\$ 4.3$ billion. ${ }^{37}$ Smart meters are an essential component of the system, allowing bidirectional communications over power lines so that information such as real-time electricity price can be transmitted to electricity users in homes, offices and factories. Those users or their communications-enabled 'smart devices' can then react accordingly, in some cases opting to shift non-time-sensitive electricity-consuming activities to a time of day when the real-time price is lower.

The deployment of smart meters has not been entirely straightforward however. Some users complained of higher usage levels and higher electricity bills once the smart meters were installed..$^{38}$ Grid operators responded that this was due to the greatly increased sensitivity of smart grids that enabled them to detect very small but persistent loads such as DC transformers for phone chargers. Despite such bumps in the road, a grid architecture that reliably transmits information as well as electricity is vital to the success of DSM measures. The announcement in November 2014 that Shenzhen would take the lead in decoupling grid company revenues from actual power sales, thereby opening the door to removing disincentives for utilities to reduce electricity usage, is an important step in a larger programme to allow efficiency and demand-side behavioural changes to be treated as positives in the generation ledger, not simply as negatives in the demand ledger. ${ }^{39}$ Given that reforms to separate generation from transmission and to reduce monopolistic practices and pricing began in the late 1990s, such a step is long overdue. 


\section{Conclusion}

On 18 April 2014, less than a week before Earth Day, Chinese Premier Li Keqiang addressed the National Energy Commission to lay out priorities for reforming China's energy sector. ${ }^{40}$. Li's call for increased development of nuclear power along the east coast 'at the appropriate time' captured the headlines, and his promotion of large hydropower cascades in the west, along with unconventional fossil fuels such as coal-bed methane and tight shale gas, followed shortly behind. Yet he also noted that a reformed Chinese energy sector must focus on improving efficiency of energy use across the economy, including more efficient electricity dispatch models. As increases in end-use efficiency and renewable energy sources - including intermittent sources such as solar and wind - combine to alter China's electricity load profile, power grid operators will need to depend on better electricity dispatch models in order to ensure balance ${ }^{41}$ on the grid and minimize wasteful use of traditional energy sources at times when renewables are abundant.

There is reason for optimism about a dramatically different energy future for China. Continued reliance on fossil-fuels for the vast majority of primary energy and electricity in China will have tangible and costly effects on the environment, people, economy and social stability of China. For a government whose first priority is the maintenance of social stability, the business-as-usual approach to energy provision and use is simply not a viable option for the coming decades. Central government support of large-scale pilots in efficiency, and precedent-setting installations of renewables such as wind, solar and hydropower is encouraging, though the fondness for mega-projects such as the Three Gorges Project and other world firsts may not always prioritize the solutions with the greatest overall ration of benefits to costs, when those costs are fully counted. As noted above, though, hydroelectricity will continue to play an important role in China's electricity and overall energy mix, and perhaps a larger role than is currently foreseen if improvements in grid operation lead to greater reliance on hydropower in order to offset the intermittency of solar and wind power. ${ }^{42}$ Of China's 23,000 rivers with watersheds over $100 \mathrm{~km}^{2}$, the country's principal hydropower planning institute in Beijing estimates that more than 3,800 have hydroelectric potential of more than $10 \mathrm{MW} .{ }^{43}$

Further cause for guarded optimism lies in the results of recent and ongoing studies examining various scenarios for a renewable, low-carbon energy future for China. In 2012, China's Energy Research Institute (ERI) 
and China National Renewable Energy Center (CNREC) undertook the '2050 High-Penetration Renewables Study and Roadmap', ${ }^{44}$ which aimed to examine the feasibility of high renewables in the power sector by 2050, as well as lay out technological and policy strategies for achieving that goal. While the results of the study have not yet been fully released to the public, initial reports suggest the findings, while promising, may be somewhat modest in terms of the level of renewables found to be economically feasible and technologically sound from a grid stability perspective. A second study published recently by WWF and the Energy Research Transition Institute estimated that generating 80 per cent of China's electricity from renewable sources by 2050 was both technically and economically feasible (Chandler et al. 2014). The WWF study examined four scenarios - Baseline, High Efficiency, High Renewables, and Low Carbon Mix - and found that the High Renewables scenario (built on High Efficiency but prioritizing renewable supplies where available) was both technologically and economically feasible, and preferable, due to its simultaneous focus on improving efficiency, reducing emissions and eliminating new construction of nuclear power.

Finally, a study by US-based energy think-tank Rocky Mountain Institute demonstrated that a non-fossil-powered United States by 2050 is not only economically and technically feasible, but economically quite compelling at a cumulative net saving of some $\$ 5$ trillion compared to the business-as-usual case (Lovins and Rocky Mountain Institute 2011). RMI is currently undertaking a similar study in China to determine the extent to which China's power, industrial, building and transportation sectors could be de-fossilized by 2050 . While China's hydropower endowments mean hydroelectricity will play a larger role in China's electricity mix than in the US, the role of end-use efficiency will also be significant, as suggested by the light bulb example at the beginning of this article. Following the promising findings of its US study, RMI, along with China's Energy Research Institute and Lawrence Berkeley National Lab's China Energy Group, is currently applying the Reinventing Fire methodology of efficiency and renewables to China. Specifically, the study aims to determine just how great a role efficiency and renewables could play in the China's energy mix in 2050, and departs significantly from the 'build more supply' model that has largely guided the development of China's power sector thus far.

Reinventing Fire - China is ambitious and adopts a different prioritization of solutions, beginning with radically decreasing demand through end-use efficiency in the power sector, along with three other sectors 
(buildings, transportation and industry) that all have their own electric power demands. Once all economically and technically feasible efficiencies have been realized, the methodology stipulates that the second tranche of power needs be met with renewables. Here, some adaption of the methodology may be necessary due to the different policy priority nuclear power is likely to have in China, despite its less-than-promising economic characteristics, primarily from a risk pricing perspective in a post-Fukushima world where private investors are increasingly unwilling to underwrite that risk. Thus 'renewables' may have to include what Chinese energy planners refer to as 'non-fossil' (fei huashi) and 'clean' (qingjie) sources.

RMI's approach strongly prioritizes solutions that are economically feasible with very short to negative payback times, but recognizes that certain changes in the way inputs and outputs such as coal, carbon dioxide and kilowatt-hours are priced may be necessary to make those economic advantages more apparent. Two areas that are emphasized more strongly in the RMI study than in existing studies are integrative design and distributed renewables. Integrative, whole system design describes a systems approach that tries to capture multiple benefits from single components, targeting systems as simple as a supporting beam in a building that also provides thermal mass, or as complex as a city (Lovins 2010). China's massive urbanization push from now to 2030 will mean many new cities will be built from the ground-up, allowing efficiencies to be designed into the city systematically rather than retrofitted later. Meanwhile, a focus on maximizing distributed renewables as part of China's developing grid architecture supports grid reliability, a key government priority, through larger geographic balance areas for renewables and decreased costs for long-distance transmission, both the financial costs of construction and maintenance and the energy costs of line losses. One can only hope that the results of studies such as the three mentioned here reinforce each other and combine to make a compelling case for implementation before the costs of transitioning away from fossil fuels grow even higher.

Darrin Magee is Associate Professor of Environmental Studies at Hobart and William Smith Colleges in Geneva, New York. His primary research interests are renewable energy, water and waste issues in China. Email: magee@hws.edu 


\section{NOTES}

1 Three Gorges is controversial not merely because of its size, but also because its reservoir, over $600 \mathrm{~km}$ long, displaced some 1.3 million people and radically changed aquatic and riparian habitats for a number of species, including the baiji (Yangtze freshwater dolphin), now suspected to be extinct. The Three Gorges Dam reservoir is also suspected as a culprit in the devastating 2008 earthquake in Wenchuan, as the sheer weight from the reservoir's water likely triggered the quake in a fault-ridden and quake-prone area of western China.

2 Heating, Ventilation and Air-Conditioning.

3 A study released in 2013 by the Ministry of Water Resources put the figure at 22,909 rivers, a downward revision from earlier estimates of more than 50,000. MWR claimed that newer, more reliable technologies and practices for accounting for these rivers was the primary reason, but also admitted that climate change and economic development patterns play a role. See http:/ / www.mwr.gov.cn/2013pcgb/merge1. pdf. Accessed 22 April 2014.

4 See China Institute of Water and Hydropower Planning (IWHR) 2011 report, 'Shuidian kaifa de xianzhuang he qianli' (Status and Potential of Hydropower Development), available at http:/ / www.iwhr.com/zgskyww/ztbd/dbzhw/second/webinfo/2011/01/1294879660871389.html. Accessed 23 March 2014.

5 See China Electricity Council's '2013 quanguo dianli gongye tongji shuju yilanbiao' (Annual Report on National Electricity Statistical Data), available at http:/ /www.cec. org.cn/guihuayutongji/tongjxinxi/yuedushuju/2014-01-26/116224.html. Accessed 22 April 2014.

6 Ibid.

7 Author's calculation.

8 One measure of maximum theoretical efficiency of a thermal power plant is its Carnot efficiency, calculated by first taking the difference between the maximum steam temperature and the minimum condensing water temperature applicable to a given plant, then dividing that difference by the maximum temperature and multiplying the result by 100 per cent. For this calculation to work, all temperatures must be in Kelvins.

9 Author's calculations.

10 See annual reports of the Chinese Wind Energy Association (CWEA), available at http://www.cwea.org.cn.

11 See National Bureau of Statistics at http://data.stats.gov.cn/workspace/ index?m=hgnd. Accessed 10 April 2014.

12 See Energy Information Administration at http:/ / www.eia.gov/countries/countrydata.cfm?fips=CH\&trk=m\#cde. Accessed 10 April 2014.

13 For US figure, see EIA at http://www.eia.gov/countries/country-data. cfm?fips=US\#tpe. For Denmark figure, see http://www.eia.gov/countries/country-data.cfm?fips=DA\#tpe. Accessed 17 April 2014.

14 See EIA at http://www.eia.gov/countries/country-data.cfm?fips=CH\&trk=m\#cde. Accessed 12 April 2014.

15 See, for instance, Bloomberg News 6 March 2014, 'China outsourcing smog to west region stirs protest' at http://www.bloomberg.com/news/2014-03-06/china-outsourcing-smog-to-west-region-stirs-protest.html. Accessed 4 December 2014.

16 See, for instance, an article that appeared on the state-run Xinhua news website on 10 September 2014 entitled 'Hexie huajie huanjing wuran jiufen' (Harmoniously resolve environmental pollution disputes), available at http://news.xinhuanet. com/energy/2014-09/10/c_1112422960.htm. Accessed 4 December 2014.

17 According to the Chinese water quality classification system, Grades I-III are suitable 
for use and/or treatment as drinking water; Grade IV is suitable for industrial use; and Grade V is suitable for irrigation and so-called landscape use. There is also a sixth category, labeled 'V Acute' (jian wu lei) for water whose quality is poorer even than Grade V. In this classification system, 'Unfit for direct human contact' includes Grades IV, V and V Acute.

18 Full text of the law in Chinese is available at http://www.china.com.cn/chinese/ law/798072.htm. Accessed 22 April 2014.

19 Primary energy is an energy resource in its original form (e.g., crude oil, natural gas, uranium), before that resource has been transformed into a final form (e.g., refined fuels, electricity).

20 See 2012 announcement, 'Guowuyuan pizhuan fazhan gaige wei, nengyuanban guanyu jiakuai guanting xiaohuodian jizu yu yijian de tongzhi' ('State Council Approves and Transmits NDRC, Energy Office Notification on Speeding the Closure of Small Thermal Plants'), available at http:/ / www.gov.cn/zwgk/2007-01/26/content_509911.htm. Accessed 10 April 2014.

21 In Chinese, 'Cujin kuoda xiaofei xuqiu, tigao ziyuannengyuan liyong xiaolü' (Promote the Expansion of Consumption, Improve the Efficiency of the Use of Natural Resources). Full text of the policy is available on the Ministry of Commerce website at http://www.mofcom.gov.cn/aarticle/b/d/200907/20090706383517.html. Accessed 20 April 2015.22 See 2009 announcement, 'Liang bumen gonggao 'jieneng chanpin huimin gongcheng' kongtiaoqu tuiguang mulu' ('Two Ministries Announce 'EnergyEfficient Appliances Project' Promotional Catalog'), available at 'http:/ / www.gov. cn/gzdt/2009-06/02/content_1329773.htm. Accessed 10 April 2014.

23 See China Electricity Council's '2013 quanguo dianli gongye tongji shuju yilanbiao' ('Annual Report on National Electricity Statistical Data'), available at http:/ / www. cec.org.cn/guihuayutongji/tongjxinxi/yuedushuju/2014-01-26/116224.html. Accessed 22 April 2014.

24 See China Society for Hydropower Engineering (2010), 'Huaneng Xiaowan shuidianzhan nian fadianliang tupo 100 yi qianwashi' ('Huaneng Xiaowan Hydropower Station Annual Output Surpasses 10 TWh'), available at http:/ / www.hydropower. org.cn/showNewsDetail.asp?nsId=3745. Accessed 11 April 2014.

25 Author's calculations.

26 Carbon dioxide emissions figure calculated using the EIA's Calculations and References page at http://www.epa.gov/cleanenergy/energy-resources/refs.html. Accessed 20 April 2015.

27 As the name implies, Demand Side Management (DSM) practices and technologies seek to address energy supply and demand mismatch through curbing demand, rather than the more common practice of building more supply. For instance, a projected shortfall of $100 \mathrm{MW}$ in a certain portion of the power grid could either be filled by constructing a new power plant, or by finding ways to reduce demand (through better light bulbs, motors, and the like) by $100 \mathrm{MW}$.

28 Peaker plants are plants with high ramp rates $(\mathrm{MW} / \mathrm{min})$, that is, whose power output can be rapidly increased to meet an unforeseen peak in demand. More costly versions of these plants include gas turbine plants. Cheaper, though harder to site, are pumped-storage and conventional hydropower plants.

29 See the Natural Resources Defense Council's description of EPP work in Jiangsu at http:/ / www.nrdc.cn/DSM/datashare_download.php?id=1416\&cid=295. Accessed 17 April 2014.

30 See ChinaPower report on 11 February 2009, 'Jiangsu Taizhou nengxiao dianchang huo 500 wan zijin zhichi' ('Jiangsu Taizhou EPP Receives 50 Billion Yuan in Funding'), available at http:/ / www.chinapower.com.cn/newsarticle/1084/new1084235. 
asp. Accessed 19 April 2014.

31 Author's calculation.

32 Author's calculation.

33 See EPA calculator at http:/ / www.epa.gov/cleanenergy/energy-resources/calculator.html\#results. Accessed 20 April 2014.

34 Author's calculations.

35 The National Bureau of Statistics reported 698.95 TWh of hydroelectric output in 2011. An increase of 10 per cent to 769 TWh in 2013 corresponds to the increase in installed hydroelectric capacity over that same period. See http://www.stats.gov. cn/tjsj/. Accessed 22 April 2014.

36 See Natural Resources Defense Council's 'Yi butong moshi jiang 'nengxiao dianchang' xiang gengduo shengshi tazhan' ('Using Different Models to Expand EPPs to More Provinces and Cities'), available at http://www.nrdc.cn/our_program_mon. php?id=853\&cid=125. Accessed 19 April 2014.

37 A Xinhua news report on 25 February 2014 announced that at USD \$4.3 billion, China's investment in smart grid technology had surpassed that of the United States for the first time. See http:/ / news.xinhuanet.com/fortune/2014-02/25/c_119499578. htm. Accessed 23 April 2014.

38 See 2011 commentary on a Jiangxi news site, 'Gongdianju bianxiang zhangiia, zhineng dianbiao qiequ laobaixing de dianfei' ('Power bureau covertly raises prices, steals common people's electricity fees') at http://dev.jxnews.com.cn/yw/ms/view. php?id=2094. Accessed 19 April 2014.

39 See 'Shenzhen qidong shupei dianjia gaige: jin dianwang qiye dumai dumai' ('Shenzhen begins transmission and distribution pricing reforms: monopoly pricing forbidden'), available at http:/ / finance.sina.com.cn/chanjing/cyxw/20141105/01 4920731352.shtml. Accessed 4 December 2014.

40 See Xinhua report 'Li Keqiang: Shishi zai dongbu yanhai diqu qidong xinde hedian zhongdian xiangmu jianshe' ('Li Keqiang: Initiate Development of Nuclear Power on the East Coast at the Appropriate Time'), 20 April 2014, at http://news.xinhuanet. com/politics/2014-04/20/c_1110320667.htm. Accessed 22 April 2014.

41 That is, between supply and demand.

42 This is frequently referred to as 'firming' wind and solar.

43 See Institute for Water and Hydropower Research (IWHR) 2011 report, 'Shuidian kaifa de xianzhuang he qianli' ('Status and Potential of Hydropower Development'), available at http://www.iwhr.com/zgskyww/ztbd/dbzhw/second/webinfo/2011/01/1294879660871389.htm. Accessed 23 March 2014.

44 In Chinese pinyin, 'Zhongguo 2050 nian gao bilü kezaisheng nengyuan fazhan qingjing ji tujing yanjiu' ('China 2050 High-Penetration Renewables Development Scenario and Pathways Study'). See commentary on the study findings by Zhao Yongqiang, Assistant Director and Researcher at the China National Renewable Energy Centre, available at http:/ / www.ens.dk/sites/ens.dk/files/politik/Kina-samarbe jdet/Aktiviteter/Scenarier/scenario_cnrec4.pdf. Accessed 27 March 2014.

\section{REFERENCES}

Brown, Phil, Darrin Magee, and Yilin Xu 2008. 'Socioeconomic vulnerability in China's hydropower development'. China Economic Review 19 (4): 614-627.

Chandler, William, Shiping Chen, Holly Gwin, Ruosida Lin, and Yanjia Wang 2014. China's Future Generation: Assessing the Maximum Potential for Renewable Power Sources in China to 2050: WWF. Available at http:/ / www.worldwildlife.org/ pub- 
lications/china-s-future-generation-assessing-the-maximum-potential-for-renewable-power-sources-in-china-to-2050. Accessed 1 March 2014.

Chen, Huai, Yuyuan $\mathrm{Wu}$, Xingzhong Yuan, Yongheng Gao, Ning $\mathrm{Wu}$, and Dan $\mathrm{Zhu}$ 2009. 'Methane emissions from newly created marshes in the drawdown area of the Three Gorges Reservoir'. Journal of Geophysical Research: Atmospheres 114 (D18).

IPCC 2011. Special Report on Renewable Energy Sources and Climate Change Mitigation. United Kingdom and New York, NY, USA: Cambridge University Press.

Kaika, Maria 2006. 'Dams as symbols of modernization: the urbanization of nature'. Annals of the Association of American Geographers 96 (2): 276-301.

Kim, Wonnyon, Seong-Jae Doh, Yongjae Yu, and Meehye Lee 2008. 'Role of Chinese wind-blown dust in enhancing environmental pollution in Metropolitan Seoul'. Environmental Pollution 153: 333-341.

Liu, Hong 2009. 'A long-term Energy Saving Analysis on LEDs General Lighting in China'. Journal of Light and Visual Environment (Japan) 33 (2): 110-114.

Lovins, Amory B. 2010. Integrative Design: A Disruptive Source of Expanding Returns to Investments in Energy Efficiency, 8. Snowmass, Colorado: Rocky Mountain Institute. Available at http://www.rmi.org/Knowledge-Center/Library/201009_IntegrativeDesign. Accessed 20 April 2015.

Lovins, Amory B., and Rocky Mountain Institute 2011. Reinventing fire : bold business solutions for the new energy era. White River Junction, Vt.: Chelsea Green Pub.

Magee, Darrin 2006. 'Powershed Politics: Hydropower and interprovincial relations under Great Western Development'. The China Quarterly 185: 23-41.

Martinot, Eric, and Junfeng Li 2010. Renewable Energy Policy Update for China. In Renewable Energy World. Available at http://www.renewableenergyworld.com/ rea/news/article/2010/07/renewable-energy-policy-update-for-china. Accessed 19 May 2014.

McCully, Patrick 2001. Silenced Rivers: The Ecology and Politics of Large Dams. Enlarged $\&$ updated ed. New York: Zed Books.

McNally, Amy, Darrin Magee, and Aaron Wolf 2009. 'Hydropower and Sustainability: Resilience and Vulnerability in China's Powersheds'. Journal of Environmental Management 90 (Supp 3): 286-293.

Ministry of Water Resources of the PRC 2014. 2012 Nian Zhongguo Shuiziyuan Gongbao (2012 China Water Resources Report): Ministry of Water Resources. Available at http://www.mwr.gov.cn/zwzc/hygb/szygb/qgszygb/201405/t20140513_560838. html. Accessed 22 July 2014.

Scudder, Thayer 2005. The future of large dams: dealing with social, environmental and political costs. Sterling, VA: Earthscan.

Tullos, Desiree, Phil Brown, Kelly Kibler, Darrin Magee, Bryan Tilt, and Aaron Wolf 2010. 'Perspectives on the salience and magnitude of dam impacts for hydro development scenarios in China'. Water Alternatives 3 (2): 71-90.

Tullos, Desiree, Eric Foster-Moore, Darrin Magee, Bryan Tilt, Aaron Wolf, Edwin Schmitt, Francis Gassert, and Kelly Kibler 2013. 'Biophysical, socioeconomic and geopolitical vulnerabilities to hydropower development on the $\mathrm{Nu}$ River, China'. Ecology and Society 18 (3):16.

World Commission on Dams 2000. Dams and development: a new framework for decisionmaking. London: Earthscan.

Yin, Danhua, and Juan Wen 2013. 'Guangdong nengxiao dianchang xiangmu rongzi moshi chuangxin jizhi tantao ('Innovations in Finance Model Mechanisms for Efficiency Power Plants in Guangdong'). Zhongguo Nengyuan (China Energy) 35 (6): 41-44. 